\title{
Estudo de fogueiras e antracologia em contexto Proto-Jê do Sul
}

\author{
Leonardo Waisman de Azevedo (*) \\ Rita Scheel-Ybert $\left(^{*}\right)$
}

\begin{abstract}
AZEVEDO, L.W.; SCHEEL-YBERT, R. Estudo de fogueiras e antracologia em contexto
\end{abstract}
Proto-Jê do Sul. R. Museu Arq. Etn., 27: 231-237, 2016.

Resumo: O estudo de fogueiras Proto-Jê do Sul em sítios do nordeste do RS permitiu a compreensão de questões relacionadas à tecnologia de fogueiras e à economia de combustiveis destes grupos. Fez-se isso a partir de uma descrição qualitativa das fogueiras e da análise antracológica do carvão coletado em cada sítio. Encontramos elementos estruturais que operavam sobre a queima, sugerindo um conhecimento apurado sobre o processo de combustão correlato a seus usos. A análise antracológica permitiu a classificação dos tipos de lenha queimada, bem como a inferência de alguns elementos da vegetação das áreas de captação de recursos para queima.

Palavras-chave: Jê do Sul; Fogueiras; Antracologia; Economia de combustíveis; Vegetação.

\section{Introdução}

\begin{abstract}
A presentamos aqui um panorama dos resultados da dissertação de mestrado intitulada "Economia de combustíveis e tecnologia de fogueiras em sítios Proto-Jê do Sul nas terras altas do Brasil meridional", de Leonardo Waisman de Azevedo sob orientação da Profa $\mathrm{Dr}^{\mathrm{a}}$ Rita Scheel-Ybert. As fogueiras estudadas foram escavadas em sítios arqueológicos no planalto do Rio Grande do Sul, localizados na região de Pinhal da Serra, e pesquisados durante os anos 2000 pela equipe do Núcleo de Pesquisa Arqueológica da Universidade Federal do Rio Grande do Sul, em um projeto de pesquisas coordenado pela Prof ${ }^{a}$ Dr $^{\text {a Silvia Copé. }}$

A arqueologia do Planalto sempre notou a presença do fogo na maior parte dos sítios escavados. Porém, jamais estudou esse elemento de forma aprofundada, como um fator significativo em termos técnicos, sociais e simbólicos

${ }^{*}$ ) Museu Nacional/UFRJ. <leonardo_wa@yahoo.com.br> <scheelybert@mn.ufrj.br>
\end{abstract}

nas atividades das populações Proto-Jê do Sul. Considerando a constante presença de fogueiras e a importância que o fogo desempenha no cotidiano de sociedades como essa, a escassez de pesquisas nesse sentido mantinha um vazio na compreensão da arqueologia do planalto.

Motivado por isso, buscou-se compreender comportamentos e conhecimentos tradicionais relativos à produção e uso de fogueiras por esses grupos, na forma como elas foram encontradas em espaços domésticos e rituais. Fez-se isso através do estudo de caso de quatro sítios arqueológicos: duas estruturas semi-subterrâneas dos sítios Ari I e Leopoldo V, o sítio lito-cerâmico Pedreira e a estrutura de aterro anelar A, sítio Leopoldo VII.

\section{Os sítios}

Ari I

O sítio é um conjunto de estruturas semisubterrâneas, montículos de terra, uma área de concentração de material lítico e cerâmico em su- 
perfície, e um terraceamento artificial que limita a ocorrência das estruturas. Os resultados obtidos na escavação do sítio demonstraram tratar-se de um espaço doméstico (Copé 2008, 2009).

Foi analisado o material de uma das estruturas semi-subterrâneas do sítio: a casa I. A escavação de sua camada de ocupação revelou uma base circular, com bancadas e um fundo rebaixado. Foram identificadas feições de uma possível fogueira de base côncava com pedras, lentes escuras de carvão associadas a zonas de refugo de processos de limpeza da fogueira, e um possível buraco do esteio de sustentação do telhado. O material arqueológico encontrado foi material lítico e termóforas, dispostos na base da estrutura.

\section{Leopoldo V}

Outro conjunto de estruturas semi-subterrâneas, distribuídas de forma linear no topo de um morro. Seus limites são definidos pela distribuição de material na área externa às estruturas e por um terraceamento que nivela o terreno no entorno. É também uma área doméstica (Copé et al. 2002; Saldanha 2005).

Uma estrutura escavada neste sítio foi trabalhada: a casa B. A escavação da camada de ocupação mais profunda desta estrutura revelou um piso rebaixado cercado por bancadas construídas nas paredes, e uma fogueira central de base côncava e com muitas pedras. No piso foi encontrado material lítico e cerâmico disperso.

\section{Pedreira}

É um sítio lito-cerâmico formado por uma grande mancha circular de terra preta, contendo duas concentrações de material disperso. Uma dessas concentrações foi interpretada como o fundo de uma cabana pré-histórica, que teria à sua entrada uma fogueira de base côncava com pedras sobrepostas (Copé et al. 2002; Saldanha 2005).

\section{Leopoldo VII}

É um conjunto de estruturas anelares com função funerária. A escavação de uma trincheira na estrutura maior revelou a presença de uma fogueira sob o montículo central, na qual foi encontrada uma grande quantidade de fragmentos de ossos calcinados. Tratava-se de uma pira funerária com forma alongada e base côncava (Copé et al. 2002; Saldanha 2005).

\section{Aspectos metodológicos}

O material estudado foi foco de dois níveis de abordagem:

O primeiro referente a aspectos tecnológicos, desenvolvido através da análise das próprias fogueiras a partir de uma descrição qualitativa das estruturas de combustão.

A produção do fogo está diretamente relacionada às intenções de uso a que se aplica e às suas formas de preparo, e é o resultado de gestos culturais tradicionais. As características estruturais de uma fogueira, como posição, forma e elementos constitutivos, interferem diretamente no processo de combustão e em suas possibilidades de uso, e não são um acaso no processo de produção do fogo (Julien et al. 1987; Leroi-Gourhan 1988; Taborin 1989). A compreensão da existência dos gestos culturais tradicionais para fazer o fogo é útil ao se pensar técnicas empregadas pelos grupos Proto-Jê do Sul estudados neste trabalho.

O segundo nível de abordagem é referente aos combustiveis utilizados, desenvolvido a partir de uma análise antracológica do carvão coletado na escavação de cada um dos sítios, sob uma perspectiva de economia de combustíveis. O conceito de economia de combustiveis abrange a produção do fogo da coleta ao uso do combustível. Um estudo nesse sentido compreende questões quanto à área de captação e a disponibilidade de recursos, as técnicas de coleta do combustível, preferências culturais específicas, motivação para a coleta e função da fogueira, e gestão de combustíveis ao longo do tempo (Théry-Parisot 2001).

A análise antracológica consistiu na identificação taxonômica, do estado e do diâmetro mínimo das amostras de carvão (Chabal 1992; Scheel-Ybert 2004a, b). A identificação foi feita a partir da observação e caracterização anatômica do carvão em um microscópio óptico de luz re- 
fletida, com campo claro e campo escuro, através da verificação dos fragmentos nos três planos de corte fundamentais da madeira (transversal, longitudinal radial e longitudinal tangencial). Os planos foram atingidos através da quebra manual do carvão.

\section{Resultados e discussão}

\section{Posição e contexto das fogueiras}

A posição das fogueiras em cada sítio se mostrou como um elemento chave para compreender seu funcionamento e a organização do espaço interno dos assentamentos. Em áreas domésticas as fogueiras eram sempre posicionadas num espaço central, transformado em um pólo de atividades e interações sociais, e de uma maneira que favorecesse as trocas de calor no interior das estruturas (ver Théry-Parisot 2001; Copé 2006). Nos sítios cerimoniais as fogueiras também ocupavam uma posição central, e orientavam a organização espacial do ritual (Corteletti 2012; Mabilde 1987/1899) ao mesmo tempo em que poderiam funcionar como elementos de controle e ação sobre o morto e sobre os vivos (ver Crépeau 1994; Petry et al. 2007).

\section{Atributos estruturais}

A respeito de questões estruturais, todas as quatro fogueiras estudadas tinham uma base côncava, escavada no solo. As bases de forma côncava potencialmente mantinham inalterada a posição central do fogo, controlando o avanço das brasas e permitindo seu uso diversas vezes (ver Dron et al. 2003). Além disso, constituíam um fator determinante no desempenho das fogueiras durante o processo de combustão, uma vez que permitiam um rendimento maior na quantidade de combustivel utilizado (March 1992).

Cada atividade exigia e causava a presença de elementos diferentes. Nas fogueiras domésticas, os conjuntos de pedras descobertos permitiram sugerir processos de aquecimento controlado de materiais e técnicas de controle da intensidade do fogo (Coudret et al. 1989; Orilac \& Orilac 1980; Prevost-Demarkar 2002; Taborin 1989).
Na pira funerária, concreções de terra queimada são o resultado das altas temperaturas atingidas devido à função da fogueira associada à cremação de um corpo.

O processo de combustão era feito de forma controlada em todos os casos. Conheciam-se métodos de controle da temperatura em fogueiras estruturalmente semelhantes, tanto para atingir temperaturas muito altas quanto mais baixas.

\section{Análise antracológica}

O resultado da análise antracológica do carvão disperso na camada de ocupação do sítio Ari I e das amostras de carvão concentrado em fogueiras dos sítios Leopoldo V, Pedreira e Leopoldo VII revelou a presença de 23 tipos determinados taxonomicamente em 12 famílias e 12 gêneros, e cinco tipos de angiospermas indeterminados (fig. 1).

Dois aspectos apareceram como um padrão nos taxa determinados:

O primeiro é que todos são taxa que ocorrem na Floresta Ombrófila Mista (Floresta de Araucárias) que é parte do bioma Mata Atlântica. Isso era esperado para a região e está em conformidade com as descrições de vegetação e reconstituições paleoambientais existentes na bibliografia (ver Iriarte; Behling 2007; SIDOL 2014).

O segundo é de que a maioria dos taxa identificados são potencialmente vegetais pioneiros ou secundários, dependendo da espécie e das condições ambientais (Galvão et al. 1989; Lorenzi 1992; Klauberg et al. 2010; Sawczuk 2009). Vegetais desse tipo crescem na fase jovem de uma floresta, em uma etapa de sucessão secundária que se segue a algum distúrbio (Lorenzi 1992). Considerando as questões recorrentes sobre a construção de uma paisagem Proto-Jê do Sul, que apontam diversos elementos de transformação do espaço e da vegetação levados a cabo por esses grupos, é plausível considerar-se que as alterações que derivaram na formação de uma vegetação em regeneração foram o resultado de atividades antrópicas.

Com estas informações pôde-se formular uma hipótese de como seria a área de captação de recursos combustíveis dos sítios estudados: 
tratava-se provavelmente de uma paisagem bastante alterada devido à intensidade da ocupação Proto-Jê do Sul no local, com uma Floresta de Araucárias em estado de sucessão secundária próxima aos sítios, na área de impacto de suas ocupações.

A análise antracológica demonstrou ainda a inexistência de um padrão no calibre da lenha queimada, e da aparente preferência por lenhas sadias sem sinais de podridão. A coleta desta lenha provavelmente ocorria de duas formas: uma baseada no recolhimento seletivo de madeira caída na mata, e outra baseada na derrubada de árvores.

Descobriu-se a presença de dois taxa presentes como combustivel nas fogueiras que, supõe-se, seriam lenhas usadas para iniciar o processo de combustão. São eles Poaceae Bambusoideae (bambu), e Arecaceae (tronco de palmeira). Ambos são lenhas de alta inflamabilidade; as palmeiras estão relacionadas à técnica de combustão de fricção rotativa utilizada pelos grupos Jê do Sul descrita em fontes etno-históricas (ver Lavina 1994; Mabilde 1897/1899; Métraux 1946). O uso de palmeira para iniciar o processo de combustão está, ainda, associado ao mito de origem do fogo entre os Kaingang (Métraux 1946).

O uso de bambu e palmeira para aquisição do fogo é possivelmente um indicativo do emprego de uma seleção específica de combustíveis dentre os elementos vegetais disponíveis na região, motivado por termos funcionais e práticos, como a alta inflamabilidade destes taxa, ou simbólicos, como a afirmação de uma identidade Jê do Sul através da recriação de um mito (Freud 1932; Leroi-Gourhan 1988). Essa ocorrência sugere um conhecimento apurado das características de inflamabilidade de ao menos alguns elementos vegetais.

Em termos taxonômicos, as análises demonstraram que praticamente não existiam repetições nos tipos de lenha utilizadas. Os tipos evidenciados nas amostras de cada foguei-

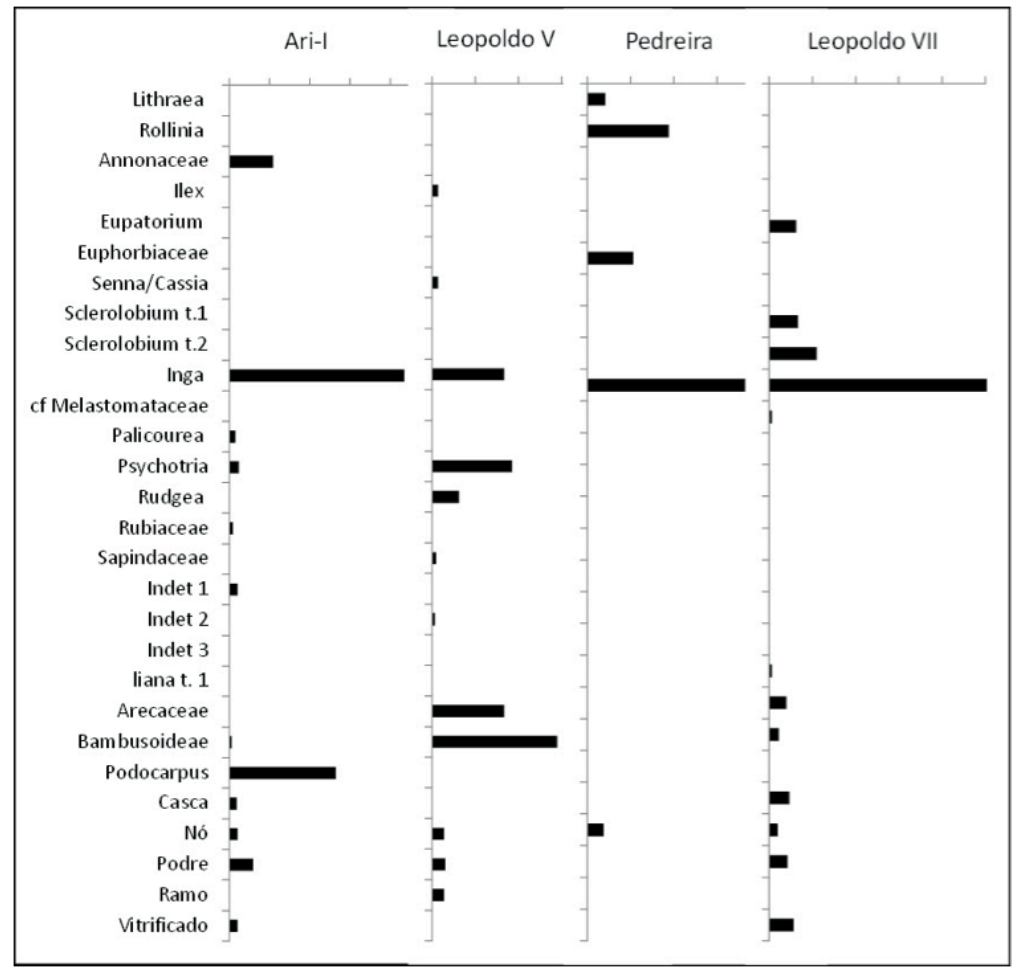

Fig. 1. Gráfico de ocorrência de tipos identificados na análise antracológica. 
ra eram majoritariamente ocorrências únicas, exceto por duas exceções relacionadas entre si: o gênero Inga e sua família Fabaceae de forma geral, que apresentaram frequências relativas significativas e uma recorrência em todos os sítios.

As Fabaceae provavelmente não estavam disponíveis em uma abundância tão significativa que justificasse seu uso intenso como combustível nas fogueiras estudadas, como demonstrado por estudos fitossociológicos desenvolvidos em diversas regiões com Floresta de Araucárias (Galvão et al. 1989; Sawczuk 2009; Klauberg et al. 2010). Ou seja, em uma coleta aleatória de madeira na mata, as lenhas de Fabaceae não seriam muito representadas. Mesmo assim, esses taxa repetiram-se em todas as fogueiras e apresentaram frequências relativas altas. Supõe- se que os taxa de Inga spp. e outras Fabaceae seriam lenhas procuradas e coletadas especificamente para seu uso na fogueira.

\section{Um comentário final}

Tem se mostrado possível, a partir de características estruturais das fogueiras, vislumbrar alguns traços do conhecimento tecnológico empregado pelos grupos Proto-Jê do Sul em sua maneira de produzir e utilizar o fogo. Também, o emprego de uma metodologia antracológica para análise do carvão coletado nestas fogueiras possibilitou a realização de inferências sobre a vegetação próxima aos sítios e sobre aspectos de uma economia de combustíveis para o fogo.

AZEVEDO, L.W.; SCHEEL-YBERT, R. The study of hearths and anthracology in Proto-Jê do Sul sites. R. Museu Arq. Etn., 27: 231-237, 2016.

\begin{abstract}
The study of hearths in Proto-Jê do Sul sites, in the northeast of RS state, allowed us to understand issues related to fire technology and fuel economy of these groups. This was done through a qualitative description of the fire structures and an anthracological analysis of each site. We found structural characteristics that influenced the combustion, suggesting an accurate knowledge of the burning process and the construction of the hearths, correlated with its uses. The anthracological analysis allowed us to classify the firewood types, and to suggest some environmental characteristics of vegetation in the firewood resources area.
\end{abstract}

Keywords: Jê do Sul; Hearth; Anthracology; Fuel economy; Vegetation.

\title{
Referências Bibliográficas
}

Chabal, L. 1992. La représentativité paléo-écologique des charbons de bois archéologiques issus du bois de feu. Bulletin de la Société Botanique de France, 139: 2-3-4: 213-236.

Copé, S.M. 2006. Les grands constructeurs précoloniaux du plateau du sud du Brésil: étude de paysages archéologiques à Bom Jesus, Rio Grande do Sul, Brésil. Tese de doutorado. Paris, Universidade de Paris I, Panthéon, Sorbonne.
Copé, S.M. 2008. Escavações arqueológicas em Pinhal da Serra, RS. Atividades de campo realizadas em 2008 e 2007. NuPArq, UFRGS, Porto Alegre, RS.

Copé, S.M. 2009. Relatório de campo da campanha arqueológica de Pinhal da Serra - 10 de janeiro a 28 de fevereiro - NuPArq UFRGS. NuPArq, UfRGS, Porto Alegre, RS. 
Copé, S.M.; Saldanha, J.D.M.; Cabral, M.P. 2002. Contribuições para a pré-história do Planalto: estudo da variabilidade de sítios arqueológicos de Pinhal da Serra, RS. In: Pesquisas, Antropologia, Instituto Anchietano de Pesquisas, São Leopoldo, 58: 121-138.

Corteletti, R. 2012. Projeto arqueológico Alto Canoas - Paraca: um estudo da presença Jê no planalto catarinense. Tese de Doutorado. MAE, USP, São Paulo.

Coudret, P.; Larriere, M.; Valentin, B. 1989. Comparer des foyers: Une entreprise difficile. In: Olive, M. ; Taborin, Y. Nature et function des foyers préhistoriques, Actes du Colloque International de Nemours 1987. Mémoires du Musée de Préhistoire d'île de France, Association pour la Promotion de la Recherche Archéologique en Île de France, Musée de Préhistoire d'île de France, Nemours, 2: 37-45.

Crépeau, R.R. 1994. Mythe et rituel chez les indiens Kaingang du Brésil Méridional. In: Religiologiques, 10: 143-157.

Dron, J.L.; Ghesquière, E.; Marcigny, C.; Chancerel, A.; Kinnes, I.; San Juan, G.; Verron, G. 2003. Les structures de combustion du Néolithique moyen en Basse-Normandie (France): proposition de classement typologique et fonctionnel. In: Actes du Colloque de Bourg-en-Bresse et Beaune, 7-8 octobre 2000. Éditions Monique Mergail.

Freud, S. Aquisição e controle do fogo. In: Novas conferências introdutórias sobre psicanálise e outros trabalhos (1932 - 1936). Volume XXII, Imago, e-book.

Galvão, F.; Kuniyoshi, Y.S.; Roderjan, C.V. 1989. Levantamento Fitossociológico das Principais Associação Arbóreas da Floresta Nacional de Irati PR. Revista Floresta, 19(1).

Iriarte, J.; Behling, H. 2007. The expansion of Araucaria Forest in the southern Brazilian highlands during the last 4000 years and its implications for the development of the Taquara/Itararé Tradition. In: Environmental Archaeology, 12: 2: 115-127.

Julien, M.; Olive, M.; Perlés, C.; Pigeot, N.; Taborin, Y.; Thiebault, S.; Valladas, H.; Wattez, J. 1987. Le feu apprivoisé, Le feu dans la vie quotidienne des hommes préhistoriques. Musée de Préhistoire d'Île-de-France.

Klauberg, C.; Paludo, G.F.; Bortoluzzi, R.L.C.; Mantovani, A. 2010. Florística e Estrutura de um Fragmento de Floresta Ombrófila Mista no Planalto Catarinense. Revista Biotemas, 23 (1): 37-47.

Lavina, R. 1994. Os Xokleng de Santa Catarina: uma etnohistória e sugestões para os arqueólogos. Dissertação de mestrado. UNISINOS, São Leopoldo.

Lorenzi, H. 1992. Árvores brasileiras: manual de identificação e cultivo de plantas arbóreas nativas do Brasil. Nova Odessa: Ed. Plantarum, 352p.

Leroi-Gourhan, A. 1988. El hombre y la materia (evolución y técnica). Madrid, Taurus.

Mabilde, A. 1987/1899. Apontamentos sobre os indígenas selvagens da nação "Coroados" que habitam os sertões do Rio Grande do Sul. Annuario do Estado do Rio Grande do Sul, Porto Alegre.

March, R.J. 1992. L'utilisation du bois dans les foyers préhistoriques: une approche expérimentale. Bulletin de la Société Botanique de France, 139: 2-3-4: 245-253.

Métraux, A. 1946. The Caingang. In: Steward, J. Handbook of South American Indians. United States Government Printing Office, Washington.

Orilac, C.; Orilac, M. 1980. Les structures de combustion et leur interprétation archéologiques: quelques exemples en Polynésie. 
Journal de la Société des Océanistes, T. XXXVI, n 66-67: 61-76.

Petry, L.; Tettamanzy, A.L.L.; Freitas, A.E.C. 2007. O papel do mito nas narrativas orais dos Kaingang na Bacia do Lago Guaíba, Porto Alegre, RS. Organon, v.21, n42.

Prevost-Demarkar, S. 2002. Les foyers et les fours domestiques en Egée au Néolithique et à l'Age du Bronze. Civilisations, Revue internationale d'anthropologie et de sciences humaines, 48: 223-237.

Saldanha, J.D.M. 2005. Paisagem, lugares e cultura material: uma arqueologia espacial nas terras altas do sul do Brasil. Dissertação de mestrado. Porto Alegre, PUCRS.

Sawczuk, A.R. 2009. Florística e Estrutura Horizontal no Periodo 2002 - 2008 de um Fragmento de Floresta Ombrófila Mista no Centro Sul do Estado do Paraná. Campus de Irati.139p. Dissertação de mestrado, Universidade Estadual do Centro-Oeste.

Scheel-Ybert, R. 2004a. Teoria e método em antracologia. 1. Considerações teóricas e perspectivas. Arquivos do Museu Nacional, Rio de Janeiro, 62: 1: 3-14.

Scheel-Ybert, R. 2004b. Teoria e método em antracologia. 2. Técnicas de campo e laboratório. Arquivos do Museu Nacional, Rio de Janeiro, 62: 4: 343-356.

SIDOL. Sistema de Identificação Dendrológica Online - Floresta Ombrófila Mista. Disponível em: www.florestaombrofilamista.com.br/, acessado em setembro de 2014.

Taborin, Y. 1989. Le foyer: Document et concept. In: Olive, M. \& Taborin, Y. Nature et function des foyers préhistoriques, Actes du Colloque International de Nemours 1987. Mémoires du Musée de Préhistoire d'île de France, 2: 77-80. Association pour la promotion de la Recherche Archéologique en Île de France, Musée de Préhistoire d'Île de France, Nemours.

Théry-Parisot, I. 2001. Économie des combustibles au Paléolithique. Expérimentation, taphonomie, anthracologie. Dossier de documentation archéologique $\mathrm{n}^{\circ} 20$, Paris, CNRS Editions. 